\title{
EAl Endorsed Transactions

\section{The observer of a direct-current moto condition on the basis of the particles swarm method}

\author{
A.N. Gargaev ${ }^{1}$, V.G. Kashirskikh ${ }^{1, *}$, A.G. Zakharova ${ }^{1}$ and V.A. Borovtsov ${ }^{2}$
}

${ }^{\mathbf{1}}$ T.F. Gorbachev Kuzbass State Technical University, Department Electric drive and automation

28, Vesennyaya St., 650000, Kemerovo, the Russian Federation.gargaevan@,kuzstu.ru,kvg.ea@kuzstu.ru,

zaharova8@gmail.com

${ }^{\mathbf{2}}$ T.F. Gorbachev Kuzbass State Technical University, Fundamental Training Faculty, Foreign Languages Department 28, Vesennyaya St., 650000, Kemerovo, the Russian Federation.dekanat.gemf@yandex.ru

\section{Abstract}

This paper describes a observer of direct current motor's (DC motors) parameter based on particles swarm method allowing to define the parameters values set and variables state in real time. During the electric motor operation the values characterizing its current state, for example, the resistance and inductances of the field winding and armature coil change over a wide range and are inaccessible for direct measurement therefore their indirect definition by means of observers is necessary. The current state of the working electric motor at the same time is defined by computer processing easily of measurands - voltage and currents of motor windings, by using of its mathematical model and estimation methods.

The mathematical processing algorithm, features of settings, performance and some other results of the research are presented in this article. The results of this work can be used in the design of sensorless DC drives. The estimated DC motor parameter's can be used for control, monitoring and diagnostics of DC drive technical state.

For check of serviceability and accuracy of the PSO method the computer motor model received on the basis of the equations of the generalized electrical machine was used. State estimation results of the working electric motor P-12 type confirmed validity of the offered approach.

Keywords: electric drive, DC motor, electromagnetic parameters, estimation, particle swarm optimization, energy efficiency.

Received on 15 June 2018, accepted on 23 September 2018, published on 31 January

Copyright (C) 2019 A.N. Gargaev et al., licensed to EAI. This is an open access article distributed under the terms of the Creative Commons Attribution licence (http://creativecommons.org/licenses/by/3.0/), which permits unlimited use, distribution and reproduction in any medium so long as the original work is properly cited.

doi: 10.4108/eai.13-7-2018.156436

\section{Introduction}

One of the main way of further increase in production efficiency is use of the modern informational technologies allowing to control a condition of processing equipment and to optimize management on this basis. Electric motor is main element of electric drive, his technical state defines reliability and safety all technological process,

"Corresponding author. Email: kvg.ea@kuzstu.ru and therefore it is necessary to have accurate information on his current state.

Though now in the industrial production the frequencyadjustable asynchronous electric drive is the most perspective, the range of application of DC motors remains still rather wide, for example, so far they are applied to creation of the main electric drives of rope shovels. Electric motors of these drives work in the repeated and short-term mode with the considerable loadings and overloads, at the same time their thermal state, parameters and variable states change. Therefore, it 
is necessary to control motor current state in the rope shovel operation course.

Information obtained from observers can be used, for example, for creation and work of subsystems of control, protection, technical condition diagnostics of the electric drive and also for prediction of maintenance terms, solving power - and resource-saving problem. The solution of these tasks requires creation of an information complex of the electric drive which basic elements will be technical state's observers.

Use of this complex constructed on the basis of the modern technical means and informational technologies will allow to increase considerably efficiency, the functional reliability and safety of the electric drive and technological installation in general.

\section{Materials and methods}

Basis of an algorithm work for a parameter estimation of DC motor is the use of target function [1]

$$
F(\bar{\beta})=\sum_{k=0}^{N}\left(I_{[k]}-I_{M[k]}\right)^{2},
$$

where $\bar{\beta}$ - a vector of parameters, $N$ - a sample size of the measured data, $I$ - the measured current of a motor anchor winding (exaltation), $I_{M}$ - the winding current received at model operation.

Target function allows to define a degree of surge characteristics approximation of the motor and its computer model. There are many estimation methods of dynamical systems, the most frequently used from them are least-square and recursive least-square methods, Kalman Filter, Search Methods, Genetic algorithms, Artificial Neural Networks [1-10]. Unlike the known algorithms of estimation developed for dynamic identification of electric motors, the PSO method allows to carry out high performance and targeted searching of a target function minimum at change of model parameters, on the basis of adaptation and algorithm parameters correction.

The optimization population algorithm is used here in which minimization of target function is made on the basis of information exchange between elements (particles). At the same time the elements collective behavior of the decentralized self-organized system is imitated. Various values of required motor's parameters are used as particles coordinates in this case. The PSO method allows to process at the same time several versions of the parallel solution of a task that considerably speeds up computing procedures. Also its wide approbation at the solution of various optimization problems belongs to advantages of this method [11-20].

For searching of an target function extremum (1) the particles move in space of required parameters, finding optimal solutions [21,22]. The current state of each particle is characterized by coordinates in space and a vector of movement speed which initial values are chosen in a random way. The dimension of a speed vector is defined by dimension of search space. At the same time wider review of search space is provided by great values of particles speed, and more precise localization of target function minimum - small values of speed.

For coordination of the movements, particles communicate, at the same time each particle stores coordinates of the best solutions found by it and also the best decision from found all particles of a swarm. Individual information of a particle and swarm is updated on each iteration and also the current speed of each particle which is used for updating of its position according to dependences:

$$
\begin{aligned}
& V_{i+1}=w \cdot V_{i}+c 1 \cdot r 1 \cdot\left(p b_{i}-X_{i}\right)+c 2 \cdot r 2 \cdot\left(g b_{i}-X_{i}\right) ; \\
& X_{i+1}=X_{i}+V_{i+1},
\end{aligned}
$$

$$
\text { where } V_{i}-\text { a vector of the current speed; }-V_{i+1} \mathrm{a}
$$
speed vector on the following iteration; $-X_{i}$ current position of a particle; $X_{i+1}$ - a particle position on the following iteration; $p b_{-}$the best individual decision; $g b_{\text {- the best group decision; }} w_{-}$the weight coefficient defining inertial properties of a particle; $c l_{-}$the weight coefficient defining personal properties of a particle; $c 2$ - the weight coefficient defining social properties of a particle; $r 1, r 2$ - random variables in the range $[0,1]$.

When the particle finds a local extremum of target function, it affects on the next particles, seeking to localize them in the same vicinity. In the same way other particles find also other local extrema among which, as a result, the global extremum is in process of searching. The effectiveness of global extremum searching of target function increases with increase in the population size and the iterations number increases accuracy of searching. However at the same time the time spent for receiving parameters estimation is increased.

\section{Results}

Test of parameters estimation possibility was carried out on the motor P-12 type during its work. The computer model of DC motor was created by the equations obtained from a generalized electric machine. Searching was carried out in space where required parameters were values of motor's electromagnetic parameters - resistance and inductances of the field winding and armature coil. For increase in efficiency of computation process the parameters estimation of anchor windings and exaltation was carried out separately.

For an example, the figure characterizing algorithm convergence processes of a motor's parameter estimation 
at different ratios of individual and social weight coefficients are submitted in the drawing. Inertial properties particles coefficient for all options $-\mathrm{w}=0.7$. The best option based on the ratio of the speed and smoothness of algorithm convergence in the searching course turned out upon the smoothly varying transition, with a step 0.01 , from social behavior of particles (s) to individual (k).

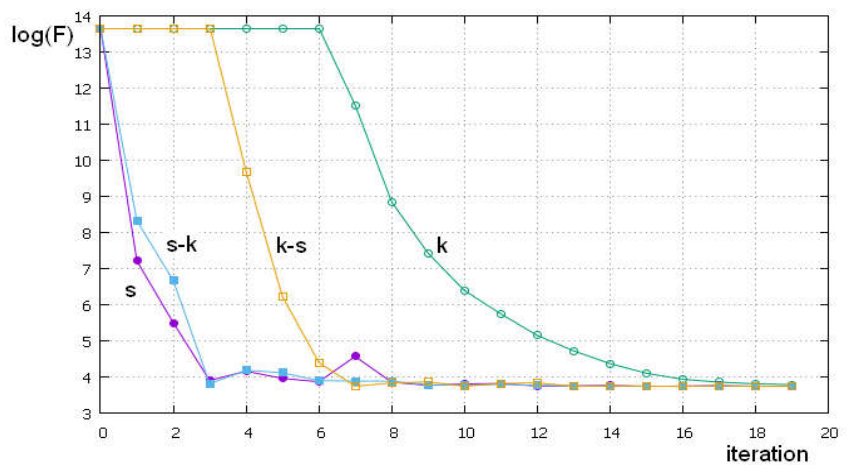

Figure. Dependences of an algorithm convergence on number of iterations.

Social behavior $(\mathrm{s})$ : $\mathrm{s} 1=0.1, \mathrm{~s} 2=1.5 ; \quad$ individual behavior $(\mathrm{k})$ : $\mathrm{s} 1=1.5, \mathrm{~s} 2=0.1$; $(\mathrm{s}-\mathrm{k})$ : at the smoothly varying change of a ratio from $\mathrm{s}$ to $\mathrm{k} ;(\mathrm{k}-\mathrm{s})$ : at the smoothly varying change of a ratio from $k$ to $s$. The values of motor parameters received at number of swarm particles, equal 100 (option A) and number of iterations, equal 500 (option B) are given in the table. In option A the number of iterations, and in option $\mathrm{B}$ - number of swarm particles are varied.

As the given parameters the average parameters values estimates of the same engine received for this mode at its dynamic identification on the basis of a least squares method and a Kalman filter are presented in the table.

Results of a parameter estimation of DC motor table

\begin{tabular}{|c|c|c|c|c|c|c|c|}
\hline \multirow[t]{3}{*}{$\begin{array}{l}\text { Para- } \\
\text { metrs }\end{array}$} & \multirow{3}{*}{$\begin{array}{l}\text { Given } \\
\text { para } \\
\text { metrs }\end{array}$} & \multicolumn{3}{|c|}{$\begin{array}{c}\text { The estimated parameters } \\
\text {-option A }\end{array}$} & \multicolumn{3}{|c|}{$\begin{array}{c}\text { The estimated } \\
\text { parameters-optionB }\end{array}$} \\
\hline & & \multicolumn{3}{|c|}{ Number of iterations } & \multicolumn{3}{|c|}{$\begin{array}{c}\text { Numberof swarm } \\
\text { particles }\end{array}$} \\
\hline & & 100 & 500 & 10 & 50 & 100 & 200 \\
\hline $\mathrm{Rv}, \mathrm{OM}$ & 185 & 332 & 185 & 185 & 332 & 185 & 185 \\
\hline $\mathrm{Lv}, \Gamma_{\mathrm{H}}$ & 50 & 2 & 50.1 & 50.1 & 2 & 50.1 & 50.1 \\
\hline $\mathrm{Rv}, \mathrm{OM}$ & 3,5 & 3.32 & 3.49 & 3.49 & 3.32 & 3.346 & 3.491 \\
\hline $\mathrm{La} \sum, \Gamma_{1}$ & 0,02 & 0.086 & 0.021 & 0.021 & 0.086 & 0.016 & 0.021 \\
\hline
\end{tabular}

Accuracy and time of a motor's parameter estimation depend on algorithm settings, sample size and range of search space. Control of an estimation algorithm was made empirically, however knowledge of approximate values of parameters and possible range of their change allows to reduce considerably searching range, to increase accuracy and to reduce estimation time. During the work of an algorithm driving to a global extremum it is expedient to reduce searching range also. The carried out researches showed that at the population size in 100 particles and in 100 iterations time of calculation is less than one second.

\section{Conclusions}

Thus, the analysis of research results shows a possibility of PSO method use for creation of the observing device allowing to define DC motor's current state in real time with an error, admissible for practical application. Information on current state of the electric motor can be used further for management, protection and diagnostics of the electric drive.

\section{References}

[1] Nesterovskiy Alexander V. Search-based dynamic identifikation of induction motors / Alexander V. Nesterovskiy, Veniamin G. Kashirskikh, Valery M. Zavyalov, Irina Y. Semykina // ARPN Journal of Engineering and Applied Sciences, Vol. 11, NO. 7, April 2016.

[2] Kashirskikh V.G., Gargaev A.N., Zavyalov V.M., Semykina I.YU. Computer system for elektric drives fault diagnosis of mining shovels $/ /$ The $8^{\text {th }}$ Russian-Chinese Symposium Coal in the $21^{\text {st }}$ Century: Mining, Processing and Safety, Vol. 274-279, 10-12 October, 2016, Kemerovo, Russia.

[3] WEI Tong. Application of adaptive Kalman filtering in system identification of brushless DC motor // WEI Tong,Rui GUO / Editorial Office of Optics and Precision Engineering, 08 August 2012

[4] Udomsuk, K-L. Areerak, K-N. Areerak and A. Srikaew. Parameters Identification of Separately Excited DC Motor using Adaptive Tabu Search Technique [text] // Sch. of Electr. Eng., Suranaree Univ. of Techonology (SUT), NakhonRatchasima, Thailand, 20 June 2010. - vol. 48 - 51

[5] Alireza REZAZADEH. Genetic Algorithm based Servo System Parameter Estimation during Transients [text] // Department of Electrical and Computer Engineering, ShahidBeheshti University, G. C, Evin, Tehran, 2010.- vol 10 , no 2 .

[6] JuggrapongTreetrong. Electric motor fault diagnosis based on parameter estimation approach using genetic algorithm, Proceedings of the international muticonference of engineers and computer scientists 2010

[7] S. Cong, X. Feng, Parameters Identification of DC Motor Based on GA and Simplex Method [text] // Control Engineering of China, 2009. - vol. 16, no. 1, P.09-112

[8] Arif A. AL-Qassar, Mazin Z. Othman. Experimental determination of electrical and mechanical parameters of dc motor using genetic elman neural network [text] // Journal of Engineering Science and Technology, 2008.vol. 3, no. 2. P. 190 - 196

[9] Feilat E. A., Maaitah E.K. Identification and control of DC motors using RBF neural network approach [text] // International conference on communication, computer and power, February 15-18, 2009, C. 258-264.

[10] Liu, H. and Huang, W. Computer numerical control machining parameter optimization based on particle swarm 
optimization. Tongji Daxue Xuebao/Journal of Tongji University, 36(6), 803-806, 2008.

[11] M. R. AlRashidi, M. E. El-Hawary. A survey of particle swarm optimization applications in electric power systems. IEEE Transactions on Evolutionary Computation : Accepted for future publication, PP:1 - 1, 2006.

[12] Hassan M. Emara, Wesam Elshamy, A. Bahgat. Parameter Identification of Induction Motor Using Modified Particle Swarm Optimization Algorithm [текст]: EEE International Symposium on Industrial Electronics Jul 2008, Cambridge, UK.

[13] Hua Bai and Bo Zhao. A survey on application of swarm intelligence computation to electric power system. In Intelligent Control and Automation, 2006. WCICA 2006. The Sixth World Congress on, pages 7587 - 7591, 2006.

[14] Penggao Wen, Meng Zhi, Guangyao Zhang, Shengmao Li. Fault Prediction of Elevator Door System Based on PSOBP Neural Network Engineering Vol.8 No.11 Pub. Date: October 31, 2016.

[15] C. Picardi, N. Rogano. Parameter identification of induction motor based on particle swarm optimization. In Power Electronics, Electrical Drives, Automation and Motion, 2006. SPEEDAM 2006. International Symposium on, pages 968 - 973, 2006.

[16] Ge Hongwei, Liang Yanchun. Identification for non-linear systems based on particle swarm optimization and recurrent neural network [ultrasonic motor control applications]. In Communications, Circuits and Systems, 2005. Proceedings. 2005 International Conference on, 2005.

[17] K. Prithivi, M. Sathyapriya, L. Ashok Kumar. Output Voltage Ripple (OVR) Reduction of Boost Converter Using Particle Swarm Optimization Circuits and Systems Vol.7 No.12 Pub. Date: October 28, 2016

[18] Jong Kwang Lee, Hyo Jik Lee, Byung Suk Park, Ji Sup Yoon. Parameter identification for position-based robot hand tracking. In SICE-ICASE, 2006. International Joint Conference, pages 3063 - 3067, 2006.

[19] J. Kennedy and R. C. Eberhart, "Particle swarm optimization," in Proceedings of the 1995 IEEE International Conference on Neural Networks, vol. 4, Perth, Australia, IEEE Service Center, Piscataway, NJ, 1995, pp. 1942-1948

[20] An Improved Particle Swarm Optimization Based on Repulsion Factor Jie Zhang, Chaozan Fan, Bo Liu, Fugui Shi Open Journal of Applied Sciences Vol.2 No.4B Pub. Date: January 15, 2013.

[21] James McCaffrey Artificial Intelligence: Particle Swarm Optimization MSDN Magazine, August, 2011.

[22] Particle Swarm Optimization Based Fuzzy-Neural Like PID Controller for TCP/AQM Router Mohammed Z. AlFaiz, Shahad A. Sadeq, Intelligent Control and Automation Vol.3 No.1 Pub. Date: February 28, 2012. 